OPEN ACCESS

Edited by:

Maw Pin Tan,

University of Malaya, Malaysia

Reviewed by:

Mario Ulises Pérez-Zepeda,

Dalhousie University, Canada

Joanna Kostka,

Medical University of Lodz, Poland

*Correspondence:

Shuhe Cai

13706989977@139.com

Liye Zou

liyezou123@gmail.com

Specialty section:

This article was submitted to

Geriatric Medicine,

a section of the journal

Frontiers in Medicine

Received: 11 June 2019 Accepted: 05 December 2019

Published: 10 January 2020

Citation:

Ye J, Simpson MW, LiU Y, Lin W, Zhong W, Cai S and Zou L (2020) The

Effects of Baduanjin Qigong on

Postural Stability, Proprioception, and

Symptoms of Patients With Knee

Osteoarthritis: A Randomized

Controlled Trial. Front. Med. 6:307.

doi: 10.3389/fmed.2019.00307

\section{The Effects of Baduanjin Qigong on Postural Stability, Proprioception, and Symptoms of Patients With Knee Osteoarthritis: A Randomized Controlled Trial}

\author{
Jiajia Ye ${ }^{1,2}$, Michael William Simpson ${ }^{2}$, Yang Liu ${ }^{3}$, Wei Lin ${ }^{4}$, Weihong Zhong ${ }^{1}$, \\ Shuhe Cai ${ }^{5,6 *}$ and Liye Zou ${ }^{7 *}$ \\ ${ }^{1}$ Department of Rehabilitation Assessment, Rehabilitation Hospital Affiliated to Fujian University of Traditional Chinese \\ Medicine, Fuzhou, China, ${ }^{2}$ Department of Rehabilitation Sciences, The Hong Kong Polytechnic University, Hong Kong, \\ China, ${ }^{3}$ Department of Kinesiology and Program in Neuroscience, Indiana University Bloomington, Bloomington, IN, \\ United States, ${ }^{4}$ Academy of Integrative Medicine, Fujian University of Traditional Chinese Medicine, Fuzhou, China, \\ ${ }^{5}$ Department of Orthopaedic Rehabilitation, Rehabilitation Hospital Affiliated to Fujian University of Traditional Chinese \\ Medicine, Fuzhou, China, ${ }^{6}$ Fujian Provincial Rehabilitation Industrial Institution, Fuzhou, China, ${ }^{7}$ Exercise and Mental Health \\ Laboratory, Shenzhen Key Laboratory of Affective and Social Cognitive Science, Shenzhen University, Shenzhen, China
}

Background: Knee osteoarthritis is a common disease affecting a large number of old individuals worldwide. This study aimed to explore the effects of Baduanjin Qigong in patients with knee osteoarthritis.

Methods: Fifty participants with knee osteoarthritis were randomly assigned to either an experimental group $(n=25)$ or a control group $(n=25)$. Participants in the experimental group received Baduanjin Qigong training for 12 weeks, with three sessions per week lasting 40 min per session. Participants in the control group did not receive any additional physical training. All of participants completed outcome (proprioception, postural stability, and functional ability) assessments at three time points (baseline, Week 8, 12).

Results: Proprioception and Western Ontario and McMaster Universities Osteoarthritis Index function were statistically improved at eighth and 12th week of the intervention in the Baduanjin Qigong group ( $p<0.05$ ), while the control group did not have any significant changes. For postural stability at the anterior-posterior direction with eyes closed, Baduanjin Qigong group showed significant improvement compared to controls after the 12 weeks of intervention $(p<0.05)$.

Conclusions: Regular Baduanjin Qigong practice helped the improvement of knee joint proprioception and postural stability, and reduction of pain, stiffness, and functional impairments of old adults with knee osteoarthritis. Well-designed randomized controlled trials with long-term assessment are needed. The trial was registered in Chinese Clinical Trial Registry (ChiCTR-IOR-16010042). URL: http://www.chictr.org.cn/hvshowproject. aspx?id=10550.

Keywords: exercise, Baduanjin, Qigong, mind-body exercise, osteoarthritis, postural stability, proprioception 


\section{INTRODUCTION}

Knee osteoarthritis (KOA) is one of the leading causes of disability, and affects $10-15 \%$ of adults aged 60 years and older globally (1). KOA as a chronic joint disease primarily involves cartilage loss and abnormal bone growth (bone spurs or osteophytes) while joint space narrowing in the knee has occurred (2). Such this degenerative process can directly lead to pain, joint stiffness, and swelling (2). Furthermore, physical function deficits (e.g., muscle strength, postural stability, and proprioception) are also observed in patients with $\operatorname{KOA}(3,4)$, which are associated with a higher incidence of falls in this population (5).

The potential mechanism of postural instability in $\mathrm{KOA}$ is complex in terms of the sensory-motor coupling (6). It is welldocumented that muscle weakness and pain are associated with impaired postural control because pain inhibits muscle activation and torque $(7,8)$. In patients with symptomatic KOA, the sensory information that fed back to the central nervous system (CNS) might be affected by unexpected conditions like pain and rough roads (9). More likely, the CNS is adaptive by the pain sensitivity and proprioception to rebuild a postural control. It indicates that the pain sensitivity may limit the sensory input of information to the CNS, which affects the motor function output of postural control (10).

Despite non-steroidal anti-inflammatory drugs (NSAIDs) aimed at reducing pain and swelling, these first-line agents are not only unaffordable to those economically disadvantaged KOA patients, but their long-term use also causes adverse effects such as gastrointestinal bleeding and perforation $(11,12)$. Physical exercise training has been shown to have the beneficial effects for patients with KOA (13). Many studies reported that postural control, proprioception, and pain sensation were statistically improved after isokinetic muscle training exercises (14-16).

In addition to this conventional training method, KOA patients also attempted to seek complementary and alternative therapies such as Qigong exercises (17), which has driven researchers to investigate their therapeutic effects for KOA patients.

Qigong exercises can reduce pain, improve functional abilities (postural stability, muscular strength, flexibility) and help KOA patients maintain normal life activities (18-22). Baduanjin Qigong (BD), one of traditional Chinese Qigong exercise (Tai Chi, Wuqinxi, and Liuzijue) therapies $(23,24)$, has a great emphasis on mind-body integration; slow body movements along with musculoskeletal stretching should be coordinated with deep breathing, physical relaxation, and mental concentration, leading to a deep state of meditative therapy $(25,26)$. Of note, $\mathrm{BD}$ with mild exercise intensity has recently received substantial attentions from the research community. As the number of trials increase, researchers subsequently conducted several systematic reviews with meta-analytic method, suggesting that $\mathrm{BD}$ has therapeutic effects for individuals with medical conditions (depression, anxiety, insomnia, chronic obstructive pulmonary disease, musculoskeletal pain, and stroke) (27-31).
However, to date, there has been only one clinical trial attempting to investigate the feasibility and safety of $\mathrm{BD}$ in treating KOA (32). Results of this previous study (32) indicated that $\mathrm{BD}$ is a safe and feasible treatment option for KOA patients as well as effective to reduce pain, stiffness, and disability (leading to better quadriceps strength and aerobic ability). Poor postural stability performance and lower-limb proprioception were also reported in these KOA patients (33-35). Given that these poor functional abilities are associated with greater possibility of fall-related injuries and death (36), it has great value to determine whether $\mathrm{BD}$ therapy has the potential to improve these outcomes while reducing pain, stiffness, and disability. Previous study involved five instructor-led sessions per week, with each $\mathrm{BD}$ session lasting $60 \mathrm{~min}$ during an 12-week intervention period (37). Such training mode/regime is hard to be realized in our hospital setting, as a result of many kinds of factor influence (e.g., transportation of patients and time-starved clinicians/researchers). Moreover, such training mode/regime does not guarantee effectiveness after the completion of intensive supervised training sessions or experiments. Whether selfpractice of $\mathrm{BD}$ would be beneficial to KOA patients is unknown. Thus, to investigate the therapeutic effects of $\mathrm{BD}$ for KOA patients, we conducted a randomized controlled trial in which a 12-week BD consisted of two phases (instructor-led training mode for first 4 weeks and home-based practice for the remaining of 8 weeks).

\section{METHODS}

\section{Study Design}

This clinical trial was designed as a randomized, single-blind, two-arm parallel assignment. We reported the study procedures and results in accordance with the CONSORT checklist (38). All eligible individuals were randomly assigned to either an experimental $\mathrm{BD}$ or control group at a 1:1 ratio via PLAN sentences of the statistical software SAS 9.1. The experimental group received a 12-week $\mathrm{BD}$ training, whereas the control group maintained their unaltered lifestyle during the study period. Before initiating, all eligible participants were asked to sign their informed consent forms, which was conducted in accordance with the declaration of Helsinki and approved by the Medical Ethics Committee of the Affiliated Rehabilitation Hospital of Fujian University of Traditional Chinese Medicine (approval number: 2014KY-020-01). The trial was registered in Chinese Clinical Trial Registry (ChiCTR-IOR-16010042).

\section{Study Participants}

Participants were recruited through advertisements and referral from their doctors of the Rehabilitation Hospital (Fujian, China) between January and December 2016. Participants were considered eligible if they: (1) were diagnosed with KOA according to criteria of the American College of Rheumatology (39), with radiographic grading of the severity between 2 and 3 (40) and knee pain of $<5$ on the 10-point Visual Analog Scale; (2) were aged between 50 and 80; (3) were able to independently ambulate without language problem in order to perform $\mathrm{BD}$ movements. We excluded those participants 
who: (1) suffered major diseases (cardiovascular, respiratory, or other musculoskeletal diseases) that required hospitalization; (2) had an implanted cardiac pacemaker; (3) were on medication affecting the musculoskeletal system, or proprioception and postural stability (e.g., anti-depressants, dopaminergic agents, and hypnotic) (41); (4) partook in regular exercise of more than three times per week; (5) fractured a bone within the past 12months.

\section{Intervention Protocol and Control Condition}

A 12-week intervention program was provided to KOA patients in the BD group, and it involved 3 sessions per week, with each session lasting $40 \mathrm{~min}$ (10 min for a warm-up and cool-down and 30-min for $\mathrm{BD}$ movements). The $\mathrm{BD}$ training regime was in line with Health Qigong-Baduanjin published by the Health-Qigong Management Center of the General Administration of Sport of China in 2003 (42). More specifically, this intervention program involved two phases. KOA patients were asked to attend groupbased BD training for first 4 weeks at the Rehabilitation Hospital, administered by a certified instructor with at least of 5 years of teaching experience. In phase 2 (Week 4-12), KOA patients were asked to practice at home. To maximize adherence to the $\mathrm{BD}$ training program, they were required to record themselves during practice. In addition, a reminder phone call was made every 2 weeks to increase exercise adherence. In the meanwhile, KOA patients were required to return to the Rehabilitation Hospital once per month and to attend the group-based $\mathrm{BD}$ training in which KOA patients were gave the opportunities to ask questions about $\mathrm{BD}$. KOA patients in the control group were informed to maintain their unaltered lifestyle while refraining from other supervised exercise training program.

To monitor their lifestyle, phone calls were made biweekly to remind these KOA patients not to involve in any extra physical exercise. After the completion of this study, KOA patients of the control group were provided with the same $\mathrm{BD}$ training program.

\section{Outcome Measures}

We collected anthropometric data [e.g., body mass index (BMI)] (Table 1) at baseline because obesity is closely related to muscle weakness and poor balance (43). Assessments of postural stability, proprioception and self-reported function were taken at three time points: baseline (Week 0), Week 8 and post-intervention (Week 12). Proprioception and postural stability assessments occurred at the Fujian Key Laboratory of Rehabilitation Technology, China. We used the Western Ontario and McMaster Universities Osteoarthritis Index (WOMAC) to assess symptoms of KOA at Fujian Key Laboratory of Integrative Medicine on Geriatrics, China. Research assistants were blinded to group assignment completed all assessments. Although blinding of participants was unrealistic during exercise intervention, to minimize performance and detection biases, we urged participants not to disclose their allocation information during the study period. All KOA patients were given time to familiarize with the outcome measures 1 week prior to the actual assessment.
TABLE 1 | Demographic data of participants

\begin{tabular}{lccc}
\hline Characteristics & $\begin{array}{c}\text { BD } \\
(\boldsymbol{n}=\mathbf{2 5})\end{array}$ & $\begin{array}{c}\text { CG } \\
(\boldsymbol{n}=\mathbf{2 5})\end{array}$ & $\boldsymbol{p}$ \\
\hline Age, year & $64.48 \pm 7.81$ & $63.08 \pm 3.65$ & 0.412 \\
Gender: females, \% & $13(52)$ & $17(68)$ & 0.333 \\
Height, cm & $163.28 \pm 7.83$ & $161.92 \pm 7.56$ & 0.535 \\
Weight, $\mathrm{kg}$ & $64.60 \pm 9.19$ & $64.20 \pm 5.70$ & 0.854 \\
Body mass index, $\mathrm{kg} / \mathrm{m}^{2}$ & $24.15 \pm 2.47$ & $24.56 \pm 2.31$ & 0.553 \\
\hline
\end{tabular}

$B D$, Baduanjin group; CG, control group.

\section{Primary Outcome Measures}

To measure postural stability, the Prokin system (PK-252, Tecnobody, Italy) was used to quantify body sway. Barefooted, participants were instructed to stand in an upright reference position on the footboard and maintain that posture for $30 \mathrm{~s}$ with their eyes open, and then with eyes closed (task was created by the machine-open first, closed after). During tests with eyes open, fixed their view on a wall position $1.5 \mathrm{~m}$ in front. Variations in center of pressure (COP) position were quantified by anteriorposterior (AP) and medial-lateral (ML) displacements measured in millimeters ( $\mathrm{mm})(9)$.

To measure postural stability and proprioception at the knee, the Prokin system was used. This system employs an electronic transducer board mounted on a pivot to record foot movement. To measure proprioception, participants were seated on a chair adjusted to the horizontal position of the participants' thigh, allowing a knee joint angle of $110^{\circ}$ and ankle plantar flexion of $10^{\circ}$. The affected foot was positioned at the center of the footboard while the other foot remained in a rest position. Participants were instructed to follow a predefined circular route with their foot. For right limb affected participants, clockwise movements were performed whereas anticlockwise movements were performed for left limb affected. Participants were instructed to perform five circular laps for each limb as fast as possible and to the best of their ability within a maximum allotted time of $60 \mathrm{~s}$. Variables of interest were average trace error (ATE) in percentage (\%) and test time execution (TTE) in seconds (s) (44).

\section{Secondary Outcome Measures}

The WOMAC is a patient-based assessment tool that involves 24 items within three subscales and has high reliability and validity (45-47). This is widely used for professionals to evaluate the condition of patients with knee or hip osteoarthritis (48). KOA patients were asked to indicate their level of pain (five items), joint stiffness (two items), and physical function (17 items) on a five-point Likert-scale, with zero representing no impairment to four representing severe impairment.

\section{Data Analysis}

The demographic data of baseline characteristics were presented with descriptive statistics. Data normality was assessed using the Shapiro-Wilk test. Individual outcome measures were assessed using two-way repeated measures ANOVA with assessment interval serving as the within-subject factor and intervention 


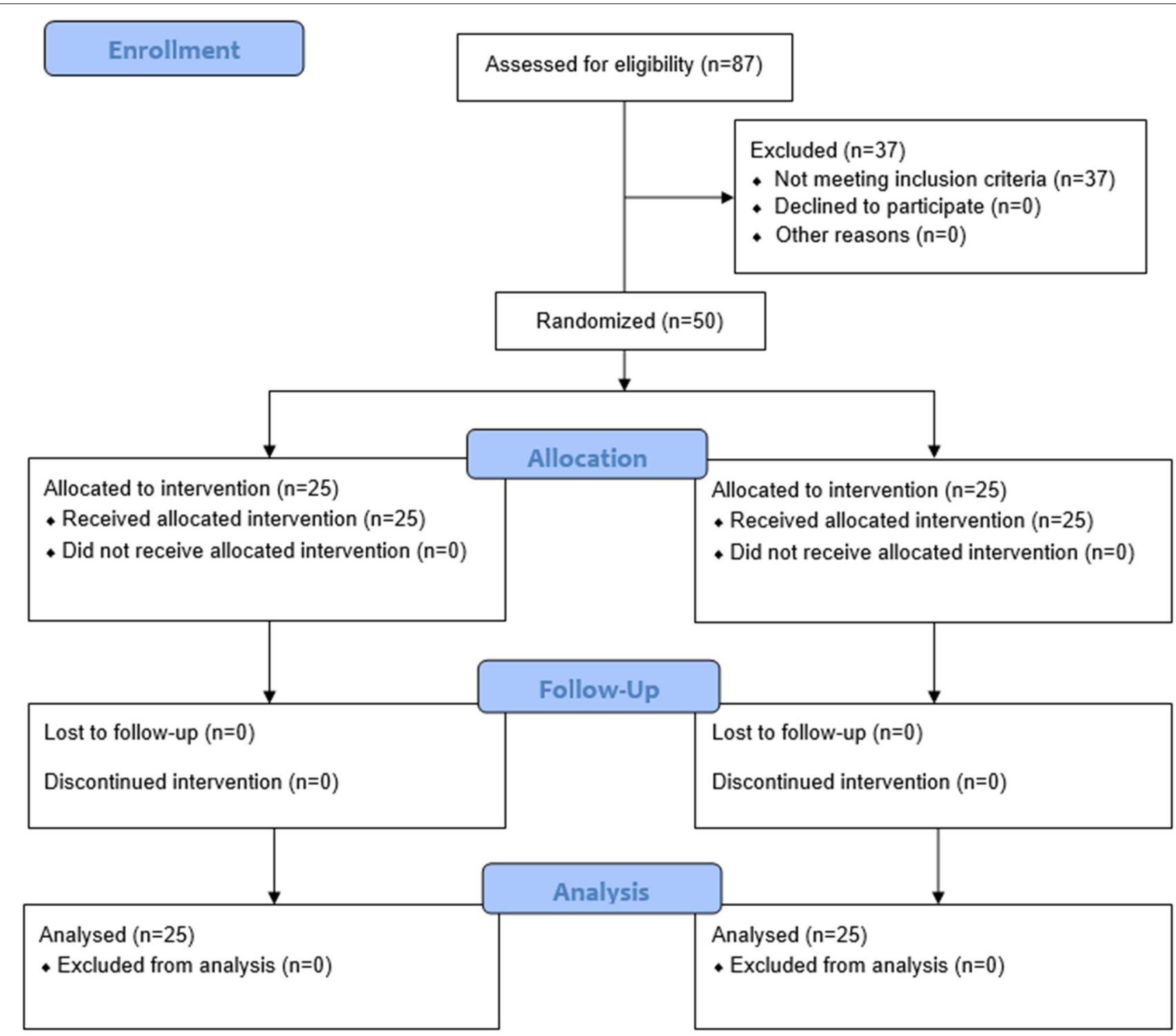

FIGURE 1 | Flow chart of the progress of all procedure.

group as the between-subject factor. If a significant interaction emerged, we used the simple effect tests. Post-hoc t-tests with Bonferroni correction were used following significant main effects. All statistical analyses were performed using SPSS 19 (IBM, New York, U.S.) using an alpha level of 0.05 to indicate a significant level.

\section{RESULTS}

A total of 87 individuals who were interested in this study replied to our research staffs, 37 of which were excluded as they did not meet inclusion criteria. Fifty participants were finally included in this study and were randomly assigned to either the BD group $(n=25$, female $=13$, male $=12)$ or the control group $(n=$ 25 , female $=17$, male $=8$ ). The average age is $64.48 \pm 7.81$ for
BD and 63.08 for the control group, respectively. Demographic information is presented in Table 1. Detailed information about study procedures are presented in Figure $\mathbf{1}$.

The primary outcomes (postural stability and proprioception) and secondary outcome (WOMAC) are presented in Table 2 . The values of all variables were similar in the two groups at baseline $(P>0.05)$. No side effect was reported during the 12 -week intervention period.

\section{Postural Stability}

For postural stability, only a significant condition-by-time interaction effect for AP direction with eyes closed $\left[F_{(1,48)}\right.$ $=3.459, p=0.035, \eta^{2}=0.067$; Table 2] was found. We ran a simple effect test to determine differences between two conditions at Week 8 and 12 (equivalent baseline). Results of 
TABLE 2 | Mean \pm SD performance value of postural stability, proprioception, and WOMAC.

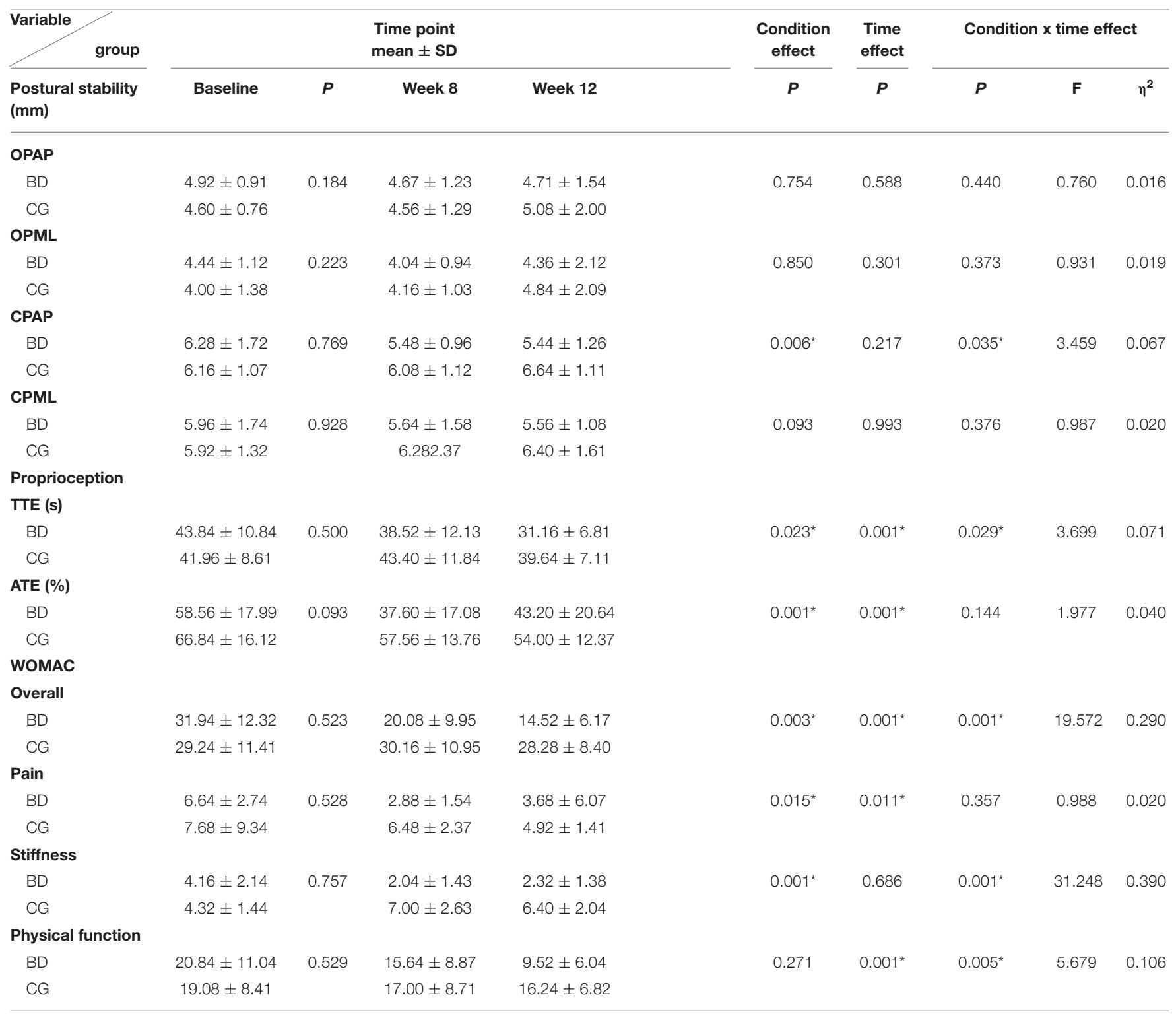

OP, open eyes; $A P$, anteroposterior; ML, mediolateral; $C P$, closed eyes; TTE, test time execution; $A T E$, average trace error; SD, standard deviation; BD, Baduanjin group; CG, control group; WOMAC, the Western Ontario and McMaster Universities Osteoarthritis Index.

${ }^{*}$ Denotes a significant effect $(P<0.05)$.

the follow-up test indicate that $\mathrm{BD}$ group showed significantly greater improvement of AP direction at both Week 8 (95\% CI -1.192 to $-0.008, p=0.047)$ and Week $12(95 \% \mathrm{CI}-1.876$ to $-0.524, p=0.001$; Tables $3 \mathbf{A}, \mathbf{B})$ than the control group. Neither group nor time effect was significant under other conditions (AP and ML with eye-open and ML with eye-closed) $(p>0.05$; Table 2).

\section{Proprioception at the Knee}

For proprioception at the knee, we observed a significant condition-by-time interaction effect for TTE $\left[F_{(1,48)}=3.669, p\right.$ $=0.029, \eta^{2}=0.071$; Table 2], but not for ATE $\left[F_{(1,48)}=1.977\right.$, $\left.p=0.144, \eta^{2}=0.040\right]$. To determine differences between two conditions at Week 8 and 12 (equivalent baseline), we ran a simple effect test, indicating that BD group showed significantly greater reduction of TTE following the 12-week intervention than the control group (Tables 3A,B). In addition, results of condition effect indicated that BD group showed significantly better performance on the ATE at both Week 8 (95\% CI -28.733 to $-11.137, p=0.001)$ and Week 12 (95\% CI -20.476 to $-1.124, p=0.029)$ as compared to those in the control group (Tables 3A,B).

\section{WOMAC}

Significant condition-by-time interaction effects were observed for overall WOMAC index $\left[F_{(1,48)}=19.572, p<0.001, \eta^{2}=\right.$ 
TABLE 3A | Results of outcome variables with post-hoc analysis over time in both groups.

\begin{tabular}{|c|c|c|c|c|c|c|c|}
\hline \multirow[t]{2}{*}{ Variable } & & \multicolumn{2}{|c|}{ Pre vs. 8 post } & \multicolumn{2}{|c|}{8 post vs. 12 post } & \multicolumn{2}{|c|}{ Pre vs. 12 post } \\
\hline & & BD & $\mathbf{C G}$ & BD & CG & BD & CG \\
\hline $\begin{array}{l}\text { OPAP } \\
(\mathrm{mm})\end{array}$ & $\begin{array}{c}P \\
95 \% \mathrm{Cl}\end{array}$ & $\begin{array}{c}0.557 \\
-0.40 \text { to } 0.72\end{array}$ & $\begin{array}{c}0.900 \\
-0.61 \text { to } 0.69\end{array}$ & $\begin{array}{c}1.00 \\
-0.95 \text { to } 0.95\end{array}$ & $\begin{array}{c}0.303 \\
-1.54 \text { to } 0.50\end{array}$ & $\begin{array}{c}0.656 \\
-0.57 \text { to } 0.89\end{array}$ & $\begin{array}{c}0.247 \\
-1.32 \text { to } 0.36\end{array}$ \\
\hline $\begin{array}{l}\text { OPML } \\
(\mathrm{mm})\end{array}$ & $\begin{array}{c}P \\
95 \% \mathrm{Cl}\end{array}$ & $\begin{array}{c}0.187 \\
-0.21 \text { to } 1.00\end{array}$ & $\begin{array}{c}0.632 \\
-0.84 \text { to } 0.52\end{array}$ & $\begin{array}{c}0.513 \\
-1.32 \text { to } 0.68\end{array}$ & $\begin{array}{c}0.223 \\
-1.80 \text { to } 0.44\end{array}$ & $\begin{array}{c}0.868 \\
-0.91 \text { to } 1.06\end{array}$ & $\begin{array}{c}0.215 \\
-2.20 \text { to } 0.52\end{array}$ \\
\hline $\begin{array}{l}\text { CPAP } \\
(\mathrm{mm})\end{array}$ & $\begin{array}{c}P \\
95 \% \mathrm{Cl}\end{array}$ & $\begin{array}{c}0.030 \\
0.09 \text { to } 1.52\end{array}$ & $\begin{array}{c}0.817 \\
-0.62 \text { to } 0.78\end{array}$ & $\begin{array}{c}0.908 \\
-0.67 \text { to } 0.75\end{array}$ & $\begin{array}{c}0.100 \\
-1.24 \text { to } 0.12\end{array}$ & $\begin{array}{c}0.074 \\
-0.09 \text { to } 1.77\end{array}$ & $\begin{array}{c}0.130 \\
-1.11 \text { to } 0.15\end{array}$ \\
\hline $\begin{array}{l}\text { CPML } \\
(\mathrm{mm})\end{array}$ & $\begin{array}{c}P \\
95 \% \mathrm{Cl}\end{array}$ & $\begin{array}{c}0.476 \\
-0.59 \text { to } 1.23\end{array}$ & $\begin{array}{c}0.519 \\
-1.50 \text { to } 0.78\end{array}$ & $\begin{array}{c}0.853 \\
-0.80 \text { to } 0.96\end{array}$ & $\begin{array}{c}0.827 \\
-1.24 \text { to } 1.00\end{array}$ & $\begin{array}{c}0.266 \\
-0.33 \text { to } 1.13\end{array}$ & $\begin{array}{c}0.286 \\
-1.39 \text { to } 0.43\end{array}$ \\
\hline \multirow[t]{2}{*}{ TTE (s) } & $P$ & 0.125 & 0.617 & $0.010^{\star}$ & 0.151 & $0.001^{*}$ & 0.361 \\
\hline & $95 \% \mathrm{Cl}$ & -1.59 to 12.23 & 7.31 to 4.43 & 7.47 to 17.89 & -2.82 to 7.46 & 1.93 to 12.79 & -1.47 to 8.99 \\
\hline \multirow[t]{2}{*}{ ATE (\%) } & $P$ & $0.001^{*}$ & 0.029 & 0.277 & 0.331 & $0.001^{*}$ & 0.018 \\
\hline & $95 \% \mathrm{Cl}$ & 11.19 to 30.73 & 1.03 to 17.53 & 4.80 to -1.11 & -3.85 to 10.97 & 8.03 to 22.69 & 2.44 to 23.24 \\
\hline $\begin{array}{l}\text { Overall } \\
\text { WOMAC }\end{array}$ & $\begin{array}{c}P \\
95 \% \mathrm{Cl}\end{array}$ & $\begin{array}{c}0.001^{*} \\
6.68 \text { to } 15.96\end{array}$ & $\begin{array}{c}0.703 \\
-5.85 \text { to } 4.01\end{array}$ & $\begin{array}{c}0.009^{\star} \\
1.49 \text { to } 9.63\end{array}$ & $\begin{array}{c}0.152 \\
-0.74 \text { to } 4.50\end{array}$ & $\begin{array}{c}0.001^{\star} \\
13.38 \text { to } 20.38\end{array}$ & $\begin{array}{c}0.696 \\
-4.04 \text { to } 5.96\end{array}$ \\
\hline \multirow[t]{2}{*}{ Pain } & $P$ & $0.001^{\star}$ & 0.541 & 0.530 & $0.003^{\star}$ & 0.049 & 0.161 \\
\hline & $95 \% \mathrm{Cl}$ & 2.40 to 4.72 & -2.80 to 5.20 & -3.39 to 1.79 & 0.60 to 2.52 & 0.02 to 5.50 & -1.18 to 6.70 \\
\hline \multirow[t]{2}{*}{ Stiffness } & $P$ & $0.001^{*}$ & $0.001^{*}$ & 0.436 & 0.321 & $0.001^{*}$ & $0.001^{*}$ \\
\hline & $95 \% \mathrm{Cl}$ & 1.20 to 3.05 & -3.71 to -1.65 & -1.01 to 0.45 & -0.62 to 1.82 & 0.99 to 2.69 & -2.91 to -1.26 \\
\hline \multirow[t]{2}{*}{ Physical function } & $P$ & $0.014^{\star}$ & 0.300 & $0.002^{\star}$ & 0.607 & $0.001^{\star}$ & 0.176 \\
\hline & $95 \% \mathrm{Cl}$ & 1.18 to 9.23 & -1.98 to 6.14 & 2.36 to 9.86 & -2.25 to 3.77 & 8.23 to 14.41 & -1.36 to 7.40 \\
\hline
\end{tabular}

*Denotes a significant effect ( $p<0.017)$; BD, Baduanjin group; CG, control group; Pre, pretest; 8 post, 8th post assessment; 12 post, 12 th post assessment.

$0.290]$, stiffness domain $\left[F_{(1,48)}=31.248, p<0.001, \eta^{2}=0.390\right]$, and physical functioning domain $\left[F_{(1,48)}=5.679, p=0.005\right.$, $\left.\eta^{2}=0.106\right]$. Results of follow-up simple effect test indicated that $\mathrm{BD}$ group showed significantly better performance on the three outcomes at Week 8 and 12 than those in the control group $(p<0.05)$. With regard to the pain domain, we observed significant group and time effect: (1) BD showed significantly better performance at Week 8 than the control group but not Week 12; (2) BD only showed significant improvement between baseline and Week $8(p=0.001)$ and between baseline and Week 12 , as significant pain reduction was observed in the control group between Week 8 and $12(p=0.003)$.

\section{DISCUSSION}

The present study investigated the effects of BD on postural stability and knee proprioception on patients with symptoms of KOA aged over 60 . Results indicated that a 12 -week BD therapy improved proprioception at the knee joint, postural stability, and WOMAC function, as compared to the control group. To date, only one study investigated the effects of BD on WOMAC indexes, results of which are consistent with the present study. Furthermore, positive findings of our study are also supported by previous studies indicating the therapeutic effects among healthy subjects for lower extremity strength (49), as well as other Qigong exercise (Tai Chi) for postural stability (50), lower-limb proprioception $(51,52)$, and WOMAC function $(51,53-55)$ of KOA patients. Thus, $\mathrm{BD}$ as a mind-body exercise therapy may be effective for treating KOA patients.
In the present study, improved proprioception of knee could be attributed to increase in quadriceps muscle strength through the 12 -week $\mathrm{BD}$ training. It has been reported that impaired proprioception of knee joint was related to quadriceps muscle weakness (56). Previous studies indicated that quadriceps strength had improved considerably after regular BD training $(32,57)$. Such positive effect on the muscle strength may provide protection against degeneration of knee proprioception. This positive effect observed in the knee proprioception may be partially explained by the feature of $\mathrm{BD}$ that has emphasis on precise control of both knee flexion and extension to maintain center of gravity while performing dynamic and symmetrical movements. The 12 -week BD intervention may provide stimulation for developing better joint position sense, leading to decrease in the ATE and TTE. It is worth emphasizing that significant improvement of knee proprioception in the BD group was only observed at Week 12, as compared to the control group.

Our results demonstrated that only $\mathrm{BD}$ group showed a significant improvement of postural stability with eye-closed at the AP direction. Furthermore, such improvement started from Week 8 and continued till Week 12. It indicates that the minimum of 8-week BD training could trigger an initial response to postural stability. Positive effects on postural stability at the AP direction may be attributed to the local muscle control (local-control) including three $\mathrm{BD}$ movements that involve postural control while upper body is required to: (1) move in multiple directions (Movement 5, Sway the Head and Shake the Tail); (2) lean forward (Movement 8, Bouncing on the Toes), (3) or take weight off the heels (Movement 8, Bouncing 
TABLE 3B | Results of outcome variables with post-hoc analysis between two groups.

\begin{tabular}{|c|c|c|c|}
\hline Variable & & 8 post & 12 post \\
\hline \multirow[t]{2}{*}{ OPAP (mm) } & $P$ & 0.579 & 0.528 \\
\hline & $95 \% \mathrm{Cl}$ & -0.59 to 0.92 & -1.33 to 0.69 \\
\hline \multirow[t]{2}{*}{ OPML (mm) } & $P$ & 0.668 & 0.498 \\
\hline & $95 \% \mathrm{Cl}$ & -0.68 to 0.44 & -1.90 to 0.94 \\
\hline \multirow[t]{2}{*}{ CPAP (mm) } & $P$ & 0.047 & $0.001^{\star}$ \\
\hline & $95 \% \mathrm{Cl}$ & -1.19 to -0.01 & -1.88 to 0.52 \\
\hline \multirow[t]{2}{*}{ CPML (mm) } & $P$ & 0.267 & 0.035 \\
\hline & $95 \% \mathrm{Cl}$ & -1.79 to -0.51 & -1.62 to -0.06 \\
\hline \multirow[t]{2}{*}{ TTE (s) } & $P$ & 0.157 & $0.001^{*}$ \\
\hline & $95 \% \mathrm{Cl}$ & -11.70 to 1.94 & -12.44 to 4.52 \\
\hline \multirow[t]{2}{*}{ ATE (\%) } & $P$ & $0.001^{\star}$ & 0.029 \\
\hline & $95 \% \mathrm{Cl}$ & -28.74 to -11.14 & -20.48 to -1.12 \\
\hline Overall & $P$ & $0.001^{\star}$ & $0.001^{\star}$ \\
\hline WOMAC & $95 \% \mathrm{Cl}$ & -16.03 to -4.13 & -17.95 to -9.57 \\
\hline \multirow[t]{2}{*}{ Pain } & $P$ & $0.001^{\star}$ & 0.325 \\
\hline & $95 \% \mathrm{Cl}$ & -4.73 to -2.47 & -3.75 to 1.27 \\
\hline \multirow[t]{2}{*}{ Stiffness } & $P$ & $0.001^{\star}$ & $0.001^{*}$ \\
\hline & $95 \% \mathrm{Cl}$ & -6.16 to -3.76 & -5.07 to -3.09 \\
\hline \multirow[t]{2}{*}{ Physical function } & $P$ & 0.587 & $0.001^{\star}$ \\
\hline & $95 \% \mathrm{Cl}$ & -6.36 to 3.64 & -10.38 to -3.06 \\
\hline
\end{tabular}

${ }^{*}$ Denotes a significant effect $(p<0.025) .8$ post, 8th post assessment; 12 post, 12 th post assessment.

on the Toes). Meanwhile, the higher central nervous sensory feedback cueing (central-control) may also contribute to this positive effect on postural stability. However, as we did not measure the central-control in present study, further work may include the measurement of control-of-gravity to investigate the performance of both local-and control-controls in patients with $\operatorname{KOA}(58,59)$.

Postural stability is the ability to defend against a fall that is prevalent in aging individuals (60). Globally, falls are the second leading cause of accidental or unintentional injury deaths, and adults aged over 65 suffer the greatest number of fatal falls (61). Roughly 40 million serious falls occur yearly which requires medical attention (62). It is widely accepted that aging population with KOA showed lower postural stability, as compared to healthy age-matched controls (63-65). Thus, prioritizing fallrelated research is critical so that we could establish effective policies to reduce risk.

Studies indicated that the quality of life among patients was largely affected by the knee pain $(66,67)$. Knee pain and stiffness would also cause psychological distress on $\operatorname{KOA}$ patients $(1,68)$. In the current study, we found with the practice of $\mathrm{BD}$, the overall WOMAC index was improved, pain and stiffness were significantly decreased compared to the control group at Week 8. Physical function domain also showed statistically significant improvement across the three time points. Previous study done by An et al. (32) was supporting the current findings. They found significant reduction in the pain subscale after 8 weeks of BD training. Another study by An et al. (57) also showed long-term BD practice would improve WOMAC outcomes. With support from previous studies, BD exercise could be an effective intervention for relieving the syndromes on pain and stiffness and improving physical function in patients with KOA.

Although we've found $\mathrm{BD}$ as an exercise intervention, is beneficial to KOA patients, the current study still has some limitations. The participants of the study were recruited from one hospital location, leading to a sampling bias of the data, the generalizability of the application was limited. Also, in the current study we compared the benefits of $\mathrm{BD}$ to a not $\mathrm{BD}$ intervention group, it is not known the effectiveness of $\mathrm{BD}$ when comparing to other type of exercises among KOA patients. Further study may include other interventions such as strength training, aerobics, or complementary and alternative exercises (i.e., Tai Chi) to compare the effects of BD exercise in participants from multi-medical centers. On another aspect, from Week 4 to 12 of the present study was home-based, some functional benefits gradually disappear within the $\mathrm{BD}$ group, this might be due to the adherence to the $\mathrm{BD}$ exercise, since it was based on participants' self-awareness, although the program motivated participants with video recording during exercise and monthly check-up at the hospital, it was challenging to measure the effort participants paid to home-based exercise. However, even with home-based practice of $\mathrm{BD}$, we still demonstrated the benefits of practicing BD on KOA patients. Finally, the sample size in each group was relatively small. This might not be enough to have the full training effects. In future studies, more advanced monitoring and supporting system could be applied to help patients keep practicing $\mathrm{BD}$, and the self-motivation of $\mathrm{BD}$ exercise among large populations should be investigated.

\section{CONCLUSION}

In summary, this study found that regular BD exercise improved proprioception of knee joint, pain, stiffness and disability in older adults with KOA. It indicates that a 12 -week BD regime (3 sessions per week, with each session lasting $40 \mathrm{~min}$ ) should be designed for KOA patients to gain positive effect of knee proprioception. Current findings indicate that the application of a $\mathrm{BD}$ program is an effective option in elderly with KOA, and home-based practice of BD could still benefit the population.

Although it is not highly recommended to practice at home without involving in domestic helpers or family members because the compliance of participants is difficult to control, it is a powerful scientific support to a good start of advocating homebased BD practice. Further work should conduct higher quality RCTs with larger sample size and long-term intervention period in patients with KOA to investigate the effectiveness of BD on postural stability (at the anterior-posterior direction with eyes closed) function. Findings of this future study may have beneficial effects in reducing fall risk for patients with KOA.

\section{DATA AVAILABILITY STATEMENT}

The datasets generated for this study are available on request to the corresponding author. 


\section{ETHICS STATEMENT}

The studies involving human participants were reviewed and approved by Local Ethics Committee (approval number: 2014KY-020-01). The trial was registered in Chinese Clinical Trial Registry (ChiCTR-IOR-16010042). The patients/participants provided their written informed consent to participate in this study.

\section{AUTHOR CONTRIBUTIONS}

JY: conceptualization. MS, WZ, and SC: data curation. JY and SC: funding acquisition. JY, WL, WZ, and SC: resources. YL, LZ, and MS: methodology. JY, MS, WL, WZ, LZ, and SC: writing - review and editing. All authors read and approved the final manuscript.

\section{REFERENCES}

1. Neogi T. The epidemiology and impact of pain in osteoarthritis. Osteoarthr Cartil. (2013) 21:1145-53. doi: 10.1016/j.joca.2013.03.018

2. Vos T, Flaxman AD, Naghavi M, Lozano R, Michaud C, Ezzati M, et al. Years lived with disability (YLDs) for 1160 sequelae of 289 diseases and injuries 1990-2010: a systematic analysis for the Global Burden of Disease Study 2010. Lancet. (2012) 380:2163-96. doi: 10.1016/S0140-6736(12)61729-2

3. Leung ES, Tsang WW. Comparison of the kinetic characteristics of standing and sitting Tai Chi forms. Disabil Rehabil. (2008) 30:1891-900. doi: 10.1080/09638280802358563

4. Sharma L. Proprioceptive impairment in knee osteoarthritis. Rheum Dis Clin. (1999) 25:299-314. doi: 10.1016/S0889-857X(05)70069-7

5. Lephart SM, Pincivero DM, Giraido JL, Fu FH. The role of proprioception in the management and rehabilitation of athletic injuries. Am J Sports Med. (1997) 25:130-7. doi: 10.1177/036354659702500126

6. Masui T, Hasegawa Y, Yamaguchi J, Kanoh T, Ishiguro N, Suzuki S. Increasing postural sway in rural-community-dwelling elderly persons with knee osteoarthritis. J Orthop Sci. (2006) 11:353-8. doi: 10.1007/s00776-006-1034-9

7. Ciubotariu A, Arendt-Nielsen L, Graven-Nielsen T. Localized muscle pain causes prolonged recovery after fatiguing isometric contractions. Exp Brain Res. (2007) 181:147-58. doi: 10.1007/s00221-007-0913-4

8. Henriksen M, Rosager S, Aaboe J, Graven-Nielsen T, Bliddal H. Experimental knee pain reduces muscle strength. J Pain. (2011) 12:460-7. doi: 10.1016/j.jpain.2010.10.004

9. Hirata RP, Jorgensen TS, Rosager S, Arendt-Nielsen L, Bliddal H, Henriksen $\mathrm{M}$, et al. Altered visual and feet proprioceptive feedbacks during quiet standing increase postural sway in patients with severe knee osteoarthritis. PLoS ONE. (2013) 8:e71253. doi: 10.1371/journal.pone.0071253

10. Hirata RP, Skou ST, Simonsen O, Rasmussen S, Laursen M, Graven-Nielsen T. Increased postural stiffness during challenging postural tasks in patients with knee osteoarthritis with high pain sensitization. Clin Biomech. (2019) 61:129-35. doi: 10.1016/j.clinbiomech.2018.12.004

11. Fendrick AM, Greenberg BP. A review of the benefits and risks of nonsteroidal anti-inflammatory drugs in the management of mildto-moderate osteoarthritis. Osteopath Med Prim Care. (2009) 3:1. doi: 10.1186/1750-4732-3-1

12. Titchen T, Cranswick N, Beggs S. Adverse drug reactions to nonsteroidal anti-inflammatory drugs, COX-2 inhibitors and paracetamol in a paediatric hospital. $\mathrm{Br} J$ Clin Pharmacol. (2005) 59:718-23. doi: 10.1111/j.1365-2125.2005.02444.x

13. Bannuru RR, Osani MC, Vaysbrot EE, Arden NK, Bennell K, Bierma-Zeinstra SMA, et al. OARSI guidelines for the non-surgical management of knee, hip, and polyarticular osteoarthritis. Osteoarthr Cartil. (2019) 27:1578-89. doi: 10.1016/j.joca.2019.06.011

\section{FUNDING}

This work was supported by Natural Science Foundation of Fujian Province of China (Grant No. 2014J01347), National Natural Science Foundation of China (Grant No. 81173316), and Central Guide to Local Science and Technology Development (Grant No. 2018L3009). Equipment was supported by Fujian Provincial Rehabilitation Industrial Institution, Fujian Key Laboratory of Rehabilitation Technology, and Fujian Key Laboratory of Integrative Medicine on Geriatrics.

\section{ACKNOWLEDGMENTS}

Authors would like to thank Ms. Duo Ye and Shijie Liu for their modification of figures. Mr. Lisong Wang for recruiting subjects, and all participants for acceptance to join the study.

14. Bouet V, Gahery Y. Muscular exercise improves knee position sense in humans. Neurosci Lett. (2000) 289:143-6. doi: 10.1016/S0304-3940(00)01297-0

15. Samut G, Dincer F, Ozdemir O. The effect of isokinetic and aerobic exercises on serum interleukin-6 and tumor necrosis factor alpha levels, pain, and functional activity in patients with knee osteoarthritis. Mod Rheumatol. (2015) 25:919-24. doi: 10.3109/14397595.2015.1038425

16. Van der Esch M, Steultjens M, Harlaar J, Knol D, Lems W, Dekker J. Joint proprioception, muscle strength, and functional ability in patients with osteoarthritis of the knee. Arthritis Care Res. (2007) 57:787-93. doi: 10.1002/art.22779

17. Wang C. Complementary and alternative medicine and osteoarthritis. Int J Integr Med. (2013) 1:13. doi: 10.5772/56431

18. Carneiro É, Moraes G, Terra G. Effects of Isha Hatha Yoga on core stability and standing balance. Adv Mind Body Med. (2016) 30:4-10.

19. Chang WD, Chen S, Lee CL, Lin HY, Lai PT. The effects of Tai Chi Chuan on improving mind-body health for knee osteoarthritis patients: a systematic review and meta-analysis. Evid Based Complement Altern Med. (2016) 2016:1813979. doi: 10.1155/2016/1813979

20. de Oliveira G, Tavares Mda C, de Faria Oliveira JD, Rodrigues MR, Santaella DF. Yoga training has positive effects on postural balance and its influence on activities of daily living in people with multiple sclerosis: a pilot study. Explore. (2016) 12:325-32. doi: 10.1016/j.explore.2016.06.005

21. Lee HY. [Comparison of effects among Tai-Chi exercise, aquatic exercise, and a self-help program for patients with knee osteoarthritis]. Taehan Kanho Hakhoe Chi. (2006) 36:571-80. doi: 10.4040/jkan.2006.36. 3.571

22. Song R, Roberts BL, Lee E-O, Lam P, Bae S-C. A randomized study of the effects of t'ai chi on muscle strength, bone mineral density, and fear of falling in women with osteoarthritis. J Altern Complement Med. (2010) 16:227-33. doi: 10.1089/acm.2009.0165

23. Zou L, SasaKi JE, Wang H, Xiao Z, Fang Q, Zhang M. A systematic review and meta-analysis Baduanjin Qigong for health benefits: randomized controlled trials. Evid Based Complement Altern Med. (2017) 2017:4548706. doi: 10.1155/2017/4548706

24. Ye J, Cai S, Zhong W, Cai S, Zheng Q. Effects of tai chi for patients with knee osteoarthritis: a systematic review. J Phys Ther Sci. (2014) 26:1133-7. doi: $10.1589 /$ jpts.26.1133

25. Ye J, Cheung WM, Tsang HWH. The neuroscience of nonpharmacological traditional chinese therapy (NTCT) for major depressive disorder: a systematic review and meta-analysis. Evid Based Complement Altern Med. (2019) 2019:2183403. doi: 10.1155/2019/2183403

26. Zou L, Pan Z, Yeung A, Talwar S, Wang C, Liu Y, et al. A review study on the beneficial effects of Baduanjin. J Altern Complement Med. (2018) 24:324-35. doi: $10.1089 / \mathrm{acm} .2017 .0241$ 
27. Jiang YH, Tan C, Yuan S. Baduanjin exercise for insomnia: a systematic review and meta-analysis. Behav Sleep Med. (2017) 4:1-13. doi: 10.1080/15402002.2017.1363042

28. Liu SJ, Ren Z, Wang L, Wei GX, Zou L. Mind(-)body (Baduanjin) exercise prescription for chronic obstructive pulmonary disease: a systematic review with meta-analysis. Int J Environ Res Public Health. (2018) 15E1830. doi: 10.3390/ijerph15091830

29. Zou L, Wang C, Chen X, Wang H. Baduanjin exercise for stroke rehabilitation: a systematic review with meta-analysis of randomized controlled trials. Int J Environ Res Public Health. (2018) 15:E600. doi: 10.3390/ijerph15 040600

30. Zou L, Yeung A, Quan X, Boyden SD, Wang H. A systematic review and meta-analysis of mindfulness-based (Baduanjin) exercise for alleviating musculoskeletal pain and improving sleep quality in people with chronic diseases. Int J Environ Res Public Health. (2018) 15:E206. doi: 10.3390/ijerph15020206

31. Zou L, Yeung A, Quan X, Hui SS, Hu X, Chan JSM, et al. Mindfulnessbased Baduanjin exercise for depression and anxiety in people with physical or mental illnesses: a systematic review and meta-analysis. Int J Environ Res Public Health. (2018) 15:E231. doi: 10.3390/ijerph15020321

32. An B, Dai K, Zhu Z, Wang Y, Hao Y, Tang T, et al. Baduanjin alleviates the symptoms of knee osteoarthritis. J Altern Complement Med. (2008) 14:167-74. doi: 10.1089/acm.2007.0600

33. Chen Y, Yu Y, He CQ. Correlations between joint proprioception, muscle strength, and functional ability in patients with knee osteoarthritis. Sichuan Da Xue Xue Bao Yi Xue Ban. (2015) 46:880-4.

34. Hatfield GL, Morrison A, Wenman M, Hammond CA, Hunt MA. Clinical tests of standing balance in the knee osteoarthritis population: systematic review and meta-analysis. Phys Ther. (2016) 96:324-37. doi: $10.2522 /$ ptj.20150025

35. Zou L, Han J, Li C, Yeung AS, Hui SS, Tsang WWN, et al. Effects of Tai Chi on lower limb proprioception in adults aged over 55: a systematic review and meta-analysis. Arch Phys Med Rehabil. (2018) 100:1102-13. doi: 10.1016/j.apmr.2018.07.425

36. Bergland A, Wyller TB. Risk factors for serious fall related injury in elderly women living at home. Inj Prev. (2004) 10:308-13. doi: 10.1136/ip.2003.004721

37. Li M, Fang Q, Li J, Zheng X, Tao J, Yan X, et al. The effect of Chinese traditional exercise-Baduanjin on physical and psychological well-being of college students: a randomized controlled trial. PLOS ONE. (2015) 10:e0130544. doi: 10.1371/journal.pone.0130544

38. Moher D, Hopewell S, Schulz KF, Montori V, Gotzsche PC, Devereaux PJ, et al. CONSORT 2010 explanation and elaboration: updated guidelines for reporting parallel group randomised trials. Int J Surg. (2012) 10:28-55. doi: 10.1016/j.ijsu.2011.10.001

39. Wu CW, Morrell MR, Heinze E, Concoff AL, Wollaston SJ, Arnold EL, et al. Validation of American College of Rheumatology classification criteria for knee osteoarthritis using arthroscopically defined cartilage damage scores. Semin Arthritis Rheum. (2005) 35:197-201. doi: 10.1016/j.semarthrit.2005.06.002

40. Kellgren JH, Lawrence JS. Radiological assessment of osteo-arthrosis. Ann Rheum Dis. (1957) 16:494-502. doi: 10.1136/ard.16.4.494

41. Ye J, Ng G, Yuen $\mathrm{K}$. Acute effects of whole-body vibration on trunk muscle functioning in young healthy adults. $J$ Strength Cond Res. (2014) 28:2872-9. doi: 10.1519/JSC.0000000000 000479

42. Abbott R, Lavretsky H. Tai Chi and Qigong for the treatment and prevention of mental disorders. Psychiatr Clin N Am. (2013) 36:109-19. doi: 10.1016/j.psc.2013.01.011

43. Jadelis K, Miller ME, Ettinger WH Jr, Messier SP. Strength, balance, and the modifying effects of obesity and knee pain: results from the Observational Arthritis Study in Seniors (oasis). J Am Geriatr Soc. (2001) 49:884-91. doi: 10.1046/j.1532-5415.2001.49178.x

44. Bagnato S, Boccagni C, Boniforti F, Trinchera A, Guercio G, Letizia G, et al. Motor dysfunction of the "non-affected" lower limb: a kinematic comparative study between hemiparetic stroke and total knee prosthesized patients. Neurol Sci. (2009) 30:107-13. doi: 10.1007/s10072-009-0031-0
45. Bellamy N, Buchanan WW, Goldsmith CH, Campbell J, Stitt LW. Validation study of WOMAC: a health status instrument for measuring clinically important patient relevant outcomes to antirheumatic drug therapy in patients with osteoarthritis of the hip or knee. J Rheumatol. (1988) 15:1833-40.

46. Guermazi M, Mezganni M, Yahia M, Poiraudeau S, Fermanian J, Elleuch $\mathrm{M}$, et al. Translation and construct validity of the Lequesne index for Arab speaking North African patients with osteoarthritis of the knee. Ann Readapt Med Phys. (2004) 47:195-203. doi: 10.1016/j.annrmp.2004. 02.008

47. Wolfe F, Kong SX. Rasch analysis of the Western Ontario MacMaster questionnaire (WOMAC) in 2205 patients with osteoarthritis, rheumatoid arthritis, and fibromyalgia. Ann Rheum Dis. (1999) 58:563-8. doi: 10.1136/ard.58.9.563

48. McConnell S, Kolopack P, Davis AM. The Western Ontario and McMaster Universities Osteoarthritis Index (WOMAC): a review of its utility and measurement properties. Arthritis Care Res. (2001) 45:453-61. doi: 10.1002/1529-0131(200110)45:5<453::AID-ART365>3.0.CO;2-W

49. Zeng Y, Zhou X, Wang A, Yang B, Wang S. Research on the impacts of fitness Qigong-Baduanjin on figure and physical function among the middle-aged and aged people. J Beijing Univ Phys Educ. (2005) 28:1207-9.

50. Ghandali E, Moghadam ST, Hadian MR, Olyaei G, Jalaie S, Sajjadi E. The effect of Tai Chi exercises on postural stability and control in older patients with knee osteoarthritis. J Bodyw Mov Ther. (2017) 21:594-8. doi: 10.1016/j.jbmt.2016.09.001

51. Qingguang Z, Lingyan H, Jingxian L, Lijuan M, Yunya Z, Fang M, et al. Effect of Taijiquan practice versus wellness education on knee proprioception in patients with knee osteoarthritis: a randomized controlled trial. J Trad Chin Med. (2017) 37:774-81. doi: 10.1016/S0254-6272(18)30040-2

52. Schmid A, McAlindon T, Schmid CH, Wang C. The influence of Tai Chi exercise on proprioception in patients with knee osteoarthritis: results from a pilot randomized controlled trial. Int J Integr Med. (2013) 1:37. doi: $10.5772 / 57137$

53. Wang C, Schmid CH, Iversen MD, Harvey WF, Fielding RA, Driban JB, et al. Comparative effectiveness of Tai Chi versus physical therapy for knee osteoarthritis: a randomized trial. Ann Intern Med. (2016) 165:77-86. doi: 10.7326/M15-2143

54. Zhang Y, Huang L, Su Y, Zhan Z, Li Y, Lai X. The effects of traditional chinese exercise in treating knee osteoarthritis: a systematic review and meta-analysis. PLoS ONE. (2017) 12:e170237. doi: 10.1371/journal.pone.01 70237

55. Zhu Q, Huang L, Wu X, Wang L, Zhang Y, Fang M, et al. Effects of Tai Ji Quan training on gait kinematics in older Chinese women with knee osteoarthritis: a randomized controlled trial. J Sport Health Sci. (2016) 5:297303. doi: 10.1016/j.jshs.2016.02.003

56. Wang C, Schmid CH, Hibberd PL, Kalish R, Roubenoff R, Rones R, et al. Tai Chi is effective in treating knee osteoarthritis: a randomized controlled trial. Arthritis Rheum. (2009) 61:1545-53. doi: 10.1002/art.24832

57. An BC, Wang Y, Jiang X, Lu HS, Fang ZY, Wang Y, et al. Effects of Baduanjin () exercise on knee osteoarthritis: a one-year study. Chin J Integr Med. (2013) 19:143-8. doi: 10.1007/s11655-012-1211-y

58. Collins JJ, De Luca CJ. Open-loop and closed-loop control of posture: a random-walk analysis of center-of-pressure trajectories. Exp Brain Res. (1993) 95:308-18. doi: 10.1007/BF00229788

59. Ehsani H, Mohler J, Marlinski V, Rashedi E, Toosizadeh N. The influence of mechanical vibration on local and central balance control. J Biomech. (2018) 71:59-66. doi: 10.1016/j.jbiomech.2018.01.027

60. Chen HH, Yeh ML, Lee FY. The effects of Baduanjin qigong in the prevention of bone loss for middle-aged women. Am J Chin Med. (2006) 34:741-7. doi: 10.1142/S0192415X06004259

61. Takacs J, Carpenter MG, Garland SJ, Hunt MA. The role of neuromuscular changes in aging and knee osteoarthritis on dynamic postural control. Aging Dis. (2013) 4:84-99.

62. Petrella M, Neves TM, Reis JG, Gomes MM, Oliveira RD, Abreu DC. Postural control parameters in elderly female fallers and non-fallers diagnosed or not with knee osteoarthritis. Rev Bras Reumatol. (2012) 52:512-7. doi: 10.1590/S0482-50042012000400004 
63. Hsieh RL, Lee WC, Lo MT, Liao WC. Postural stability in patients with knee osteoarthritis: comparison with controls and evaluation of relationships between postural stability scores and international classification of functioning, disability and health components. Arch Phys Med Rehabil. (2013) 94:340-6. doi: 10.1016/j.apmr.2012. 09.022

64. Reis JG, Gomes MM, Neves TM, Petrella M, de Oliveira RD, de Abreu DC. Evaluation of postural control and quality of life in elderly women with knee osteoarthritis. Rev Bras Reumatol. (2014) 54:208-12. doi: 10.1016/j.rbr.2013.11.002

65. Sanchez-Heran A, Agudo-Carmona D, Ferrer-Pena R, Lopez-de-UraldeVillanueva I, Gil-Martinez A, Paris-Alemany A, et al. Postural stability in osteoarthritis of the knee and hip: analysis of association with pain catastrophizing and fear-avoidance beliefs. $P M \& R$. (2016) 8:618-28. doi: 10.1016/j.pmrj.2015.11.002

66. Jones CA, Voaklander DC, Johnston DW, Suarez-Almazor ME. Health related quality of life outcomes after total hip and knee arthroplasties in a community based population. J Rheumatol. (2000) 27:17 45-52.
67. Kawano MM, Araújo ILA, Castro MC, Matos MA. Assessment of quality of life in patients with knee osteoarthritis. Acta Ortop Bras. (2015) 23:307-10. doi: 10.1590/1413-785220152306150596

68. Desmeules F, Dionne CE, Belzile E, Bourbonnais R, Fremont P. Waiting for total knee replacement surgery: factors associated with pain, stiffness, function and quality of life. BMC Musculoskelet Disord. (2009) 10:52. doi: $10.1186 / 1471-2474-10-52$

Conflict of Interest: The authors declare that the research was conducted in the absence of any commercial or financial relationships that could be construed as a potential conflict of interest.

Copyright (C) 2020 Ye, Simpson, Liu, Lin, Zhong, Cai and Zou. This is an open-access article distributed under the terms of the Creative Commons Attribution License (CC $B Y)$. The use, distribution or reproduction in other forums is permitted, provided the original author(s) and the copyright owner(s) are credited and that the original publication in this journal is cited, in accordance with accepted academic practice. No use, distribution or reproduction is permitted which does not comply with these terms. 